\title{
Emergency presentation of oesophageal carcinoma. An unusual case
}

\author{
T Al-Janabi, R Brown
}

A 48 year old woman was brought by ambulance to the department with a history of shortness of breath of five days duration.

Examination revealed a normotensive, tachypneic, tachycardic, afebrile woman who was in obvious respiratory distress with an audible wheeze. Her saturation was $91 \%$ on five litres of oxygen by mask on admission. Her chest examination showed bilateral basal crepitations and few expiratory crepitations in the right lung field. She received a single dose of frusemide, based on a working diagnosis of acute left ventricular failure. Her ECG showed sinus tachycardia and her chest radiograph showed a widened superior mediastinum (fig 1). Her blood gases showed a low hydrogen ion concentration, low $\mathrm{PaCO}_{2}$, low $\mathrm{PaO}_{2}$ with normal bicarbonate. A diagnosis of pulmonary embolism was considered and intravenous heparin was started. Within the next 15 minutes, she decreased her saturation further to $83 \%$ and finally to $61 \%$. Despite undergoing a rapid sequence induction and endotracheal

\author{
Department of \\ Accident and \\ Emergency, King's \\ College Hospital, \\ Denmark Hill, London \\ SE5 9RS, UK \\ Correspondence to: \\ Mr Al-Janabi, Specialist \\ Registrar in Accident and \\ Emergency \\ (tarik.al-janabi@kcl.ac.uk)
}

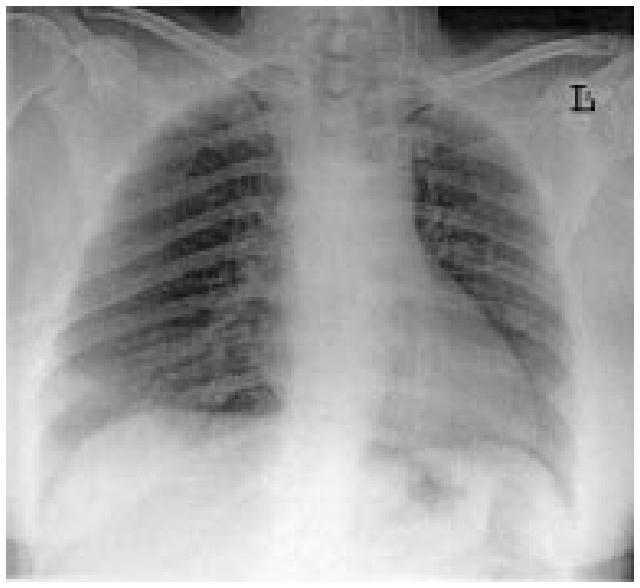

Figure 1. Chest radiograph showing widened mediastinum.

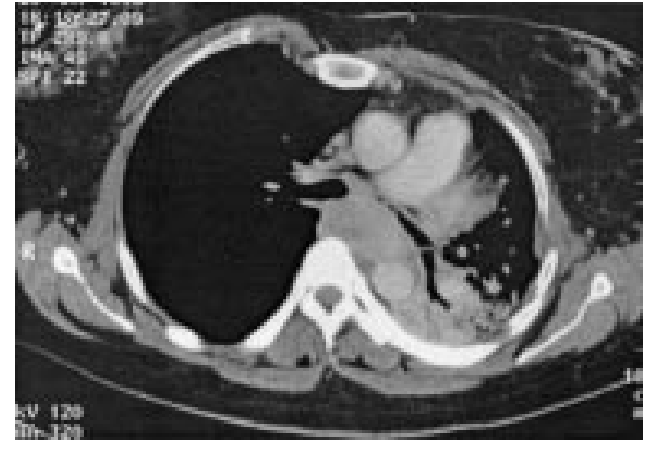

Figure 2 Spiral chest computed tomogram showing an oesophageal carcinoma invading the left main bronchus with left lung collapse.

intubation, it was difficult to maintain her saturation above $85 \%$. Urgent spiral chest computed tomography, to rule out a pulmonary embolus, showed a large mass posterior to the trachea arising from an invasive oesophageal carcinoma. The left main bronchus was narrowed to a slit with left lung collapse with compensatory hyperinflation of the right lung (fig 2).

The most common presentation of oesophageal carcinoma is progressive dysphagia. ${ }^{1}$ However, a host of other presentations have been mentioned in the literature, none the same as the one mentioned here. Fistulas to other nearby organs have been described with an emergency presentation..$^{2-4}$ Emergency physicians need to be aware of such a presentation. However, a careful ruling out of the more common causes needs to be undertaken first.

1 Schwartz S, Shires G, Spencer F. Principles of surgery. 5th ed. Singapore: McGraw Hill, 1989.

2 Garcia de Lucas MD, Ramirez Ortiz LM, Pinel Julian LM, et al. An aortoesophageal fistula as the initial manifestation of oesophageal carcinoma. Gastroenterol Hepatol 1999;22: $320-1$.

3 Avis SP. Esophageopericardial fistula. An unusual cause of sudden unexpected death. Am F Forensic Med Pathol 1999; 17:83-5.

4 Kohl O, Schaffer R, Doppl W. Purulent pericarditis as an Wochenschr 1999;124:381-5. 